\title{
Kidney outcomes for children with lupus nephritis
}

\author{
Louise Oni $^{1,2,3}$ (1) $\cdot$ Rachael D Wright $^{1} \cdot$ Stephen Marks ${ }^{4,5} \cdot$ Michael W Beresford ${ }^{1,6} \cdot$ Kjell Tullus $^{4,5}$
}

Received: 26 March 2020 / Revised: 15 June 2020 / Accepted: 18 June 2020 / Published online: 28 July 2020

(C) The Author(s) 2020

\begin{abstract}
Systemic lupus erythematosus is a rare lifelong multi-systemic autoimmune condition. Juvenile-onset SLE (JSLE) is recognized to have a more active disease course when compared with adult-onset disease and patients have a worse long-term survival. Kidney involvement occurs in over $50 \%$ of children and treatment decisions are guided by the histological classification. Several international groups have produced treatment protocols that rely on an intense period of immunosuppression to halt the acute kidney inflammatory process, followed by maintenance therapy with close observation for disease improvement and prompt evaluation of disease flares. A reduced glomerular filtration rate at presentation is predictive of later stage chronic kidney disease (CKD) in multivariate analysis. Kidney remission remains suboptimal with only $40-60 \%$ of patients achieving complete remission. Kidney flares are seen in over a third of patients. The rate of CKD 5 is reported to be up to $15 \%$ and the presence of lupus nephritis (LN) has an established link with an associated increase in mortality. In established kidney failure, transplantation seems to be the optimal kidney replacement modality for this group of patients, ideally after a period of disease quiescence. Modified outcome measures in clinical trials have demonstrated that biologic agents can be effective in this disease. Current biologic agents under investigation include obinutuzimab, belimumab, atacicept, anifrolumab, tocilizumab, eculizumab, dapirolizumab, and abatacept. Future research should focus on discovering early disease biomarkers, including surrogates for later cardiovascular disease, and evaluating biological agents as adjuncts to improve the rates of complete remission and subsequently influence the kidney outcome. The aim of this review article is to summarize the current kidney outcomes for this disease with a view to identifying key areas that may help to reduce the risk of long-term CKD.
\end{abstract}

Keywords Systemic lupus erythematosus $\cdot$ Lupus nephritis $\cdot$ SLE $\cdot$ Children $\cdot$ Prognosis $\cdot$ Childhood-onset SLE

Louise Oni

louise.oni@liverpool.ac.uk

1 Department of Women's and Children's Health, Institute of Translational Medicine, Liverpool Health Partners, University of Liverpool, Liverpool, UK

2 Department of Paediatric Nephrology, Liverpool Health Partners, Alder Hey Children's NHS Foundation Trust Hospital, Liverpool, UK

3 Paediatric Nephrology, Department of Women's and Children's Health, Institute in the Park Alder Hey Children's NHS Foundation Trust, Eaton Road, Liverpool L12 2AP, UK

4 Department of Paediatric Nephrology, Great Ormond Street NHS Foundation Trust Hospital, London, UK

5 University College London, Great Ormond Street Institute of Child Health, Biomedical Research Centre, NIHR Great Ormond Street Hospital, London WC1N 1EH, UK

6 Department of Paediatric Rheumatology, Liverpool Health Partners, Alder Hey Children's NHS Foundation Trust Hospital, Liverpool, UK

\section{Introduction}

Systemic lupus erythematosus is a lifelong autoimmune disease with multi-systemic features. It presents during childhood in around $15-20 \%$ of cases, although many patients with adult-onset disease report symptoms during adolescent years $[1,2]$. It is a relatively rare pediatric disease with an annual incidence of $0.3-2$ cases per 100,000 childhood population [3-5], with variation seen according to ethnicity and disease being more prevalent in patients of Black or Asian descent [6-8]. Juvenile-onset SLE (JSLE, also known as childhoodonset (cSLE) or pediatric SLE, pSLE) is recognized to have a more active disease course when compared with those presenting in adulthood (a-SLE), with lupus nephritis (LN) being more frequently seen [9]. Despite internationally agreed treatment protocols for $\mathrm{LN}$, the rate of kidney remission remains suboptimal, the burden of disease and its treatment remains high, and long-term survival appears to have plateaued in the past few decades. The aim of this review is to summarize the 
prognosis of childhood $\mathrm{LN}$ and to discuss areas that require improvement if we are to enhance kidney outcomes.

\section{Lupus nephritis and the development of chronic kidney disease}

Lupus nephritis (LN), defined as histologically proven disease, occurs in around $50-82 \%$ of children in comparison with 20 $40 \%$ of adults [10-12]. The extent of kidney involvement often dictates treatment choices in children with lupus. Treatment decisions are guided by the histological appearances that are graded according to the 2003 International Society of Nephrology/Renal Pathology Society (ISN/RPS) classification [13]. Several international groups have produced treatment protocols (Fig. 1) that are based on an intense period of immunosuppression, followed by maintenance therapy with close observation for disease improvement and prompt evaluation of disease flares [14-18]. The threshold to perform a kidney biopsy in LN is based on consensus recommendations suggesting that reproducible proteinuria of $>0.5 \mathrm{~g} / 24 \mathrm{~h}$ (or a urine protein:creatinine ratio $>50 \mathrm{mg} / \mathrm{mmol}$ in an early morning sample) alone should prompt performing a biopsy $[14,19]$. The majority of histologically proven disease is ISN/RPS class IV LN, the most active disease class associated with the worst kidney prognosis. Features of activity and chronicity seen histologically predict a poor kidney outcome [20].
Treatment response in LN has traditionally been assessed using "kidney remission" that is measured from various clinical components to create an ordinal end point (complete remission, partial remission, no remission). The precise definitions and time points vary between studies and their accuracy as a surrogate of disease improvement has been called into question. This has been partly due to the failure of being able to demonstrate proof of efficacy of a number of newer, mostly biologic, drugs in meeting the primary end points in doubleblind randomized controlled trials [21]. Interestingly, more recent trials with adjusted primary outcome measures have been able to demonstrate efficacy in SLE [22]. Despite this variation, it is clear that kidney remission rates remain suboptimal with only $40-60 \%$ of patients achieving so-called complete remission (using the definition of a normal serum creatinine and urine protein $\leq 0.5 \mathrm{~g} /$ day) [23]. Importantly, most pediatric nephrologists strive for complete resolution of proteinuria in children (rather than accept $\leq 0.5 \mathrm{~g} /$ day) [24]. Low rates of complete response to treatment are likely to influence the development of chronic kidney disease (CKD) due to progressive kidney damage from ongoing inflammation. This is demonstrated in a childhood retrospective study that assessed 25 children who received a follow-up biopsy 1 year after initial LN diagnosis and a statistically significantly worse histology chronicity index score had been acquired during this short follow-up [25]. These findings show that current

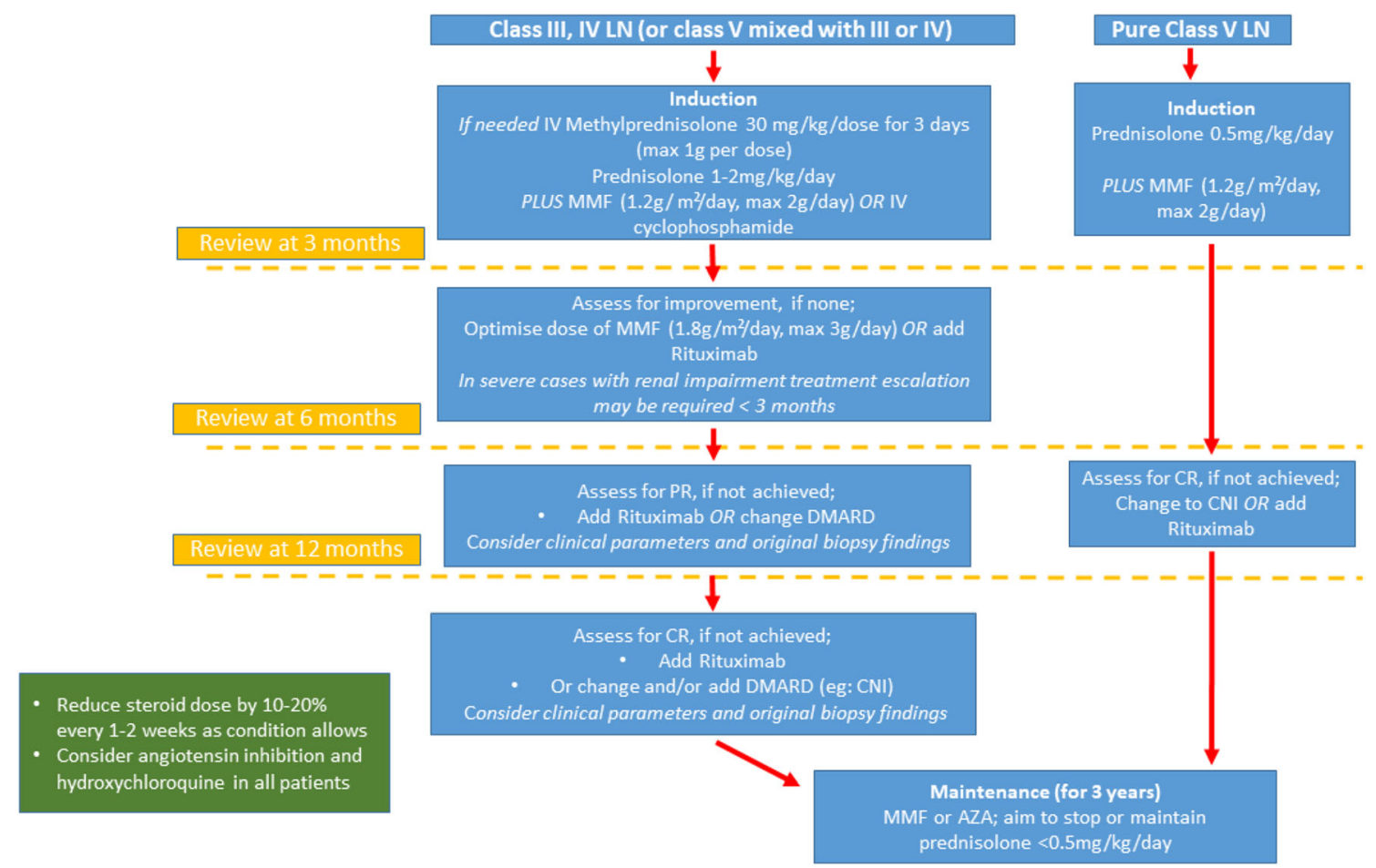

Fig. 1 A proposed treatment protocol for the induction and maintenance management of histologically class III, IV, and V lupus nephritis in children as based on published recommendations [14-18]. CR, complete response (UPCR $<50 \mathrm{mg} / \mathrm{mmol}$, normal kidney function); $\mathrm{PR}$, partial response $(>50 \%$ reduction in proteinuria, not nephrotic, normal kidney function). UPCR, urine protein:creatinine ratio; LN, lupus nephritis; DMARD, disease modifying anti-rheumatic drug; CR, complete response; PR, partial response; MMF mycophenolate mofetil; AZA, azathioprine; IV, intravenous; CNI, calcineurin inhibitor 
treatment regimens are unable to completely halt the kidney inflammatory process in the majority of patients and this contributes to damage accumulation.

In addition to initial damage, kidney flares of LN are frequently seen. A UK based adult LN cohort found that $33 \%$ of patients with histologically proven Class III or IV LN experienced a kidney flare after a mean post-induction time of 3.5 years and this seemed to be irrespective of the type of maintenance therapy used [26]. They also reported that the initial response to treatment played a significant role in the likelihood of a disease flare as $44 \%$ of partial responders experienced a subsequent kidney flare compared with only $5 \%$ of those patients who achieved an initial complete response [26]. This emphasizes the importance of aiming to achieve complete kidney remission at the outset.

There are very little specific published data with regard to the risk of developing $\mathrm{CKD}$ prior to that requiring kidney replacement therapy (CKD stage 5/ kidney failure (KF)) in children with lupus. In adults with SLE, a large nationwide French study evaluated the burden of CKD stages 3-5 (glomerular filtration rate GFR $<60 \mathrm{ml} / \mathrm{min} / \mathrm{m}^{2}$ ) [27]. It found that $6.7 \%$ of patients with LN developed CKD stage 3-5 and in the longer term CKD stage 5 was independently associated with a reduced GFR at initial presentation in multivariate analysis [27]. An initial evaluation of 399 children recruited to the UK JSLE Cohort Study [10], for the purposes of this review, demonstrated $3.8 \%$ of children had CKD stages 2-5 after an average follow-up period of 6.6 years (Fig. 2). However, the precise rates of CKD 3-5 in children from other cohorts with JSLE are unreported.

\section{Chronic kidney disease stage 5 in lupus nephritis}

Kidney involvement in SLE has been documented for over 50 years and historically it was associated with high mortality rates. Current long-term follow-up suggests the rate of CKD 5 due to LN in childhood to be up to $15 \%$ (Table 1). A Dutch study looked at the long-term follow-up (20 years) of 111 children with JSLE and found that $67 / 111(60 \%)$ had initial kidney involvement and of these 16/67 (24\%) had kidney damage including $6 / 16$ (equating to $9 \%$ of those who had initial $\mathrm{LN}$ ) required a kidney transplant at the median age of 24 years [28]. In a cohort of 54 children from New Delhi, $48 \%$ of whom had class IV LN, $6 \%$ of children developed CKD 5 over a 10 year period [29] and an Iranian cohort of 60 children ( $70 \%$ had class IV LN), 15\% developed CKD 5 with reported kidney survival rates of $98 \%, 94 \%$ and $88 \%$ for years 1,2 , and 3 after initial diagnosis, respectively [30]. A Chinese cohort in Hong Kong identified 128 children with LN and found that $51 / 128(40 \%)$ presented with kidney symptoms before initial LN diagnosis, of these 4/128 (3\%) had CKD 5 at follow-up (median 5.3 years [1-16.5]) [31]. Another cohort from Thailand identified 216 SLE patients of whom $180 \mathrm{had}$ biopsy-proven LN, 39/180 (31\%) of these patients developed kidney failure of whom 2/180 (1\%) developed CKD during follow-up (median 3.9 years [9 days-19.4 years]) [32]. In adults, the CKD 5 rates are marginally lower than in children at around 6-12\% over 10 years [26, 33-35]; however, in both groups, these figures may be influenced by the population being studied and the precise clinical and histological features within a given cohort.

In general, there are no specific contraindications to using any form of kidney replacement therapy in children with CKD stage 5 due to LN, although the coagulopathies commonly associated with this disease need to be considered. A study from Taiwan that included 94 adult patients with CKD $5 \mathrm{sec}$ ondary to LN assessed the use of different kidney replacement therapy (KRT) modalities (peritoneal dialysis, PD; hemodialysis, HD; kidney transplantation, KT) and reported better survival in the KT group and thus, like many other kidney diseases, KT seems to be the optimal modality of KRT for this group of patients [36].
Fig. 2 Using cohort data collected from children recruited to the UK JSLE Cohort Study [10], the incidence of chronic kidney disease (CKD) was $3.8 \%$ ( $15 / 399$ children) after a median follow-up time of 6.6 years (range 0-21 years). The stages of CKD are shown demonstrating that the majority of children had CKD stage $2(8 / 15 ; 53 \%, 8 / 399 ; 2 \%$ of entire cohort), followed by CKD $3(5 / 15 ; 33 \%, 5 / 399 ; 1 \%$ of entire cohort), none had CKD 4 (0/15; $0 \%, 0 / 399 ; 0 \%$ ) and 2 patients had CKD 5 (2/15; 13\%, 2/399; 0.5\% of entire cohort)

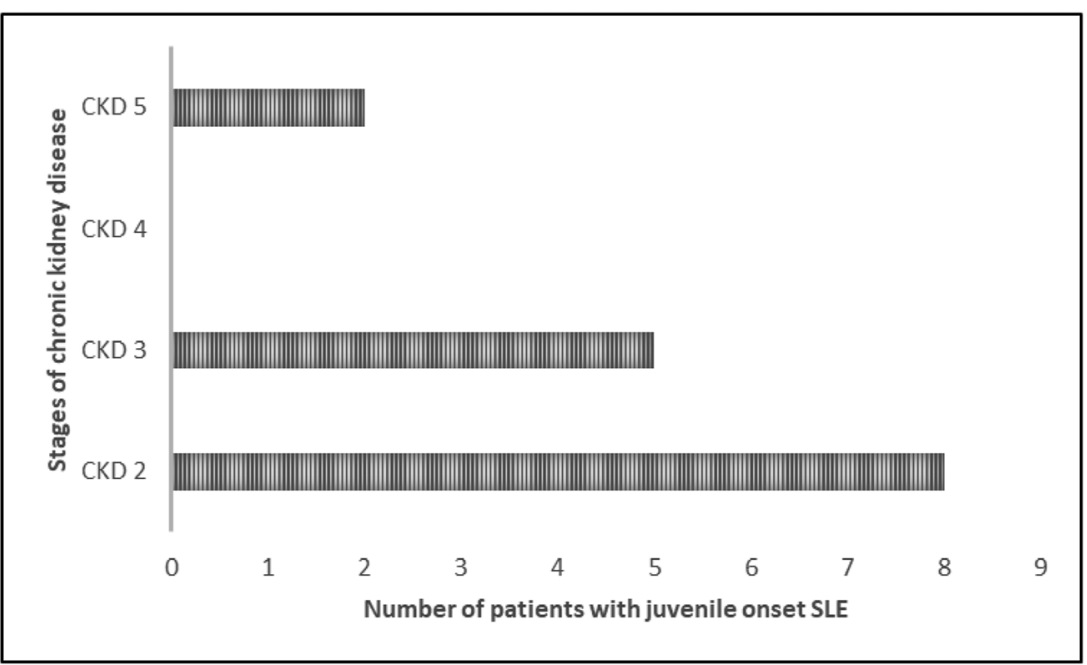


Table 1 A summary of pediatric cohorts with lupus nephritis and the frequency of chronic kidney disease CKD stage 5 (or kidney failure (KF))

\begin{tabular}{lllll}
\hline Study & $\begin{array}{l}\text { LN patient } \\
\text { number }(n)\end{array}$ & $\begin{array}{l}\text { Follow-up } \\
(\text { median [range]) }\end{array}$ & $\begin{array}{l}\text { Initial kidney } \\
\text { involvement }(n, \%)\end{array}$ & $\begin{array}{l}\text { CKD stage 5 or } \\
\text { KF }(n, \%)\end{array}$ \\
\hline $\begin{array}{l}\text { Groot et al [28] } \\
\text { Hari et al [29] }\end{array}$ & 111 & 20 years & $67 / 111(60 \%)$ & $16 / 111(14 \%)$ \\
Taheri et al [30] & 64 & 10 years & No data & $3 / 54(6 \%)$ \\
Wong et al [31] & 128 & 3 years & No data & $9 / 60(15 \%)$ \\
$\begin{array}{c}\text { Vachvanichsanong } \\
\text { et al [32] }\end{array}$ & 180 & 5.3 years [1-16.5] & $51 / 128(40 \%)$ & $4 / 128(3 \%)$ \\
\hline
\end{tabular}

\section{Kidney transplantation in lupus nephritis}

The optimal timing of performing a kidney transplant in SLE patients with CKD 5 remains uncertain and pediatric-specific data are not available. There are obvious technical risks involved in transplanting a patient with active systemic autoimmune, inflammatory disease that is associated with cytopenia, hemolysis, and pro-coagulant factors, plus active LN, could potentially develop in the new allograft [37]. The decision of when is best to transplant therefore needs to be carefully balanced against the recognized increased risks of morbidity and mortality associated with long-term dialysis. It is of the authors' opinion that a period of 6-12 months of remission should be achieved prior to transplantation to allow for systemic disease quiescence before major surgery and to ensure that there is no chance of kidney recovery, as delayed kidney improvement is reported [38]. This may require interim dialysis. Once transplanted, there is a tendency for less SLE disease flares when compared with patients on hemodialysis (flares seen in $21 \%$ of the HD group v.s $8 \%$ in KT group, $p=0.06$ ) [36] and it can be hypothesized that the efficacy of $\mathrm{KT}$ in LN patients may be, in part, due to post-transplant immunosuppression using combinations of diseasemodifying agents with or without corticosteroids and thus the medication intensity may be playing a secondary role in keeping systemic disease quiescent and preventing further disease flares [39]. In LN transplant recipients, the outcome is good with graft survival reportedly similar to that observed in controls [40], with 5-, 10-, 15-, and 20-year graft survival reported as $81 \%, 79 \%, 57 \%$ and $51 \%$, respectively (controls $89 \%, 78 \%, 64 \%$, and $56 \%$, respectively) [41].

\section{Disease-related damage to other organs}

There is a high burden of disease-associated morbidity in JSLE [42]. In general, overall morbidity is believed to be accrued secondary to persisting disease activity, a poor response to treatment, and medication side effects. Disease damage in JSLE is common with $28 \%$ of patients in the UK JSLE Cohort Study having a Systemic Lupus International
Collaborating Clinics (SLICC)/American College of Rheumatology (ACR) damage score of $\geq 1$ after a relatively short (4.5 years) follow-up period [10] and a more recent study of the same cohort demonstrated that $85 \%$ of children still had active disease after 1 year follow-up [42]. A large Dutch study evaluating 111 patients with childhood-onset lupus followed up for a median time of 20 years showed $62 \%$ of patients had experienced damage, with damage mainly in the musculoskeletal, neuropsychiatric, and kidney systems [28, 43]. In this study, damage accrual was independently associated with disease duration, antiphospholipid antibody positivity, and hypertension. The authors also demonstrated that overall the quality of life was reduced compared with the Dutch population [28]. The extent of damage and rates of accumulated damage seem to occur regardless of age in studies comparing childhood-onset and adult-onset SLE [44].

\section{Treatment-induced damage}

JSLE management can create a difficult conundrum of using intense immunosuppression to achieve disease remission whilst knowingly increasing the risk of treatment-associated side effects, including life-threatening infections and endorgan damage. Determining whether the etiology of organrelated damage is due to the disease itself or medications can be difficult.

$\mathrm{LN}$ treatment protocols heavily rely on the use of systemic corticosteroids and they are extremely useful in managing acute inflammation, yet these are typically associated with the most side effects. In the short term, corticosteroids contribute to obesity, glucose intolerance, and the development of cataracts. In the longer term, corticosteroids reduce bone density predisposing to clinical fractures and later osteoporosis, as well as worsening cardiovascular outcomes. A 12-month kidney outcome and co-morbidity study conducted by the German Society of Paediatric Nephrology in children with biopsy-proven LN noted $80 \%$ of patients had complications related to their medication use, including glucocorticoid toxicity in $42 \%$ of children and growth impairment in $78 \%$ [45]. A JSLE cohort with a longer follow-up period of 7.8 years 
demonstrated cataracts in $12 \%$ of children, avascular necrosis in $10 \%$, and growth failure in $16 \%$ and these were all associated with a younger age at diagnosis [43]. Clearly, there is an urgent need for steroid-sparing protocols in children.

Hydroxychloroquine is a useful adjunct that has been shown to improve kidney outcomes [46]. It is typically very well tolerated with few side effects. It can rarely cause retinopathy and annual ophthalmology screening is therefore recommended [14, 47]. Whilst this is rare in children, in adult patients the data shows $4.3 \%$ of patients can get retinopathy although the risk rises with the duration of treatment (> 5 years) and high therapeutic levels [48].

Mycophenolate mofetil (MMF) is an important therapeutic option for induction and maintenance treatment of LN. It is usually very well tolerated although gastro-intestinal upset is frequently seen and leucopenia is not uncommon. It is associated with some serious complications including hepatic disorders, malignancy, and hypogammaglobulinemia although the incidence of these complications as a direct result of MMF in SLE is not clear and probably very rare.

Cyclophosphamide has been the standard approach to the management of $\mathrm{LN}$ and its introduction was associated with improved outcomes. However, it is a mutagenic agent and therefore has an associated risk of malignancy (e.g., leukemia, bladder cancer) [49]. The risk of gonadal toxicity following the use of cyclophosphamide treatment remains one of its most concerning side effects. This is dependent on both cumulative dose and pubertal status. In patients with lupus, in which associated infertility due to the disease itself is not uncommon, SLE patients exposed to high cumulative doses of cyclophosphamide have an increased risk of developing infertility and premature ovarian failure than do their counterparts treated with less toxic treatments [50].

Rituximab, a chimeric monoclonal antibody, is a useful adjunctive agent in LN. However, it commonly results in infusion reactions (seen in $\sim 25 \%$ ) that can be severe and life threatening. There remains concern about John Cunningham (JC) virus reactivation, leading to progressive multifocal leukoencephalopathy (PML); however, it is very rare (reported risk $<0.5 \%$ ) and extremely rare in SLE, as it is reported mainly in patients with cancer who have received extensive chemotherapy [51]. Secondary drug-associated hypogammaglobulinemia due to chronic B cell depletion is being increasingly reported and predisposes individuals to infection. It is seen in around $4 \%$ of patients and may require lifelong immunoglobulin replacement [52].

\section{Long-term associated cardiovascular disease}

Long-term associated cardiovascular morbidity is extremely common in patients with lupus, due in part at least to the chronic inflammatory state, and this risk is increased in the presence of nephritis and contributes significantly to mortality [52]. In a study by Groot et al., reporting the long-term follow-up of childhood-onset SLE, cardiovascular complications such as myocardial infarctions began occurring after only a 5 -year disease duration and these occurred young, with the median age of having a cerebrovascular accident being 20 years and a myocardial infarction at a median age of 39 years [28]. Care models based on actively screening for cardiovascular complications can improve detection and may provide a step towards preventing long-term morbidity in this cohort [53].

\section{Lupus-associated mortality in children}

The intense immunosuppressive regimens utilized to control active $\mathrm{LN}$ increases the risk of serious infection, so the mortality associated with JSLE is usually due to infection on a background of very active disease [6] and it is a leading cause of death in SLE patients worldwide. In a UK comparison study, children with SLE had an increased standardized mortality ratio of 18.3 compared with a ratio of 3.1 reported in adult-onset SLE [53]. In India, Aggarwal et al. studied 273 children with SLE (92\% girls, median diagnosis age 14 years) over a follow-up period of 3.5 years and reported infections in 72 children (26\%), with over half of these being serious, and fourteen children $(6 \%)$ died [54]. The 5-year mortality rate for childhood lupus is reported to be between 4 and $23 \%$, with rates varying according to the age of disease onset and the population being studied [55]. Younger children have the highest mortality rates as demonstrated within JSLE cohorts, where the effect of age can be clearly seen. In a Brazilian study, children with very early-onset disease (diagnosed age $<6$ years) were predisposed to an increased risk of death (15\%) compared with those of middle childhood age (school age $\geq 6$ and $<12$ years) who had a $10 \%$ risk of mortality, and adolescents (aged $\geq 12$ and $<18$ years) who had a $6 \%$ risk of mortality [6]. Death in JSLE often occurs during the acute phase as reported in a study from Brazil (847 children), where 33/69 (48\%) of deaths occurred within the first 2 years after diagnosis [6].

Patient survival improved historically until the last few decades when it appears to have plateaued. A worldwide systematic review of SLE survival rates in both adults and children from the 1950s through to 2016, included 46,317 adult patients (from 125 adult studies) and 6,862 children (from 51 pediatric studies) from both high-income countries (HIC) and low-/middle-income countries (LMIC) [9]. The authors found that after a period of major improvement, survival in SLE has plateaued since the mid-1990s. Differences were seen when evaluating survival in children according to the nation's income with recent survival rates only improving in the children from HIC's, with 5-year and 10-year survival rates from 2008 to 2016 found to be 0.99 and 0.97 for children in HIC and only 0.85 and 0.79 for children in LMIC. This difference was not 
observed among adults. International access to pediatric care may explain some of these findings. It is not yet clear, whether medications introduced in the last decade, such as mycophenolate mofetil and rituximab, would have enhanced survival at the population level.

The presence of LN has an established link with increased associated mortality rates in SLE. A single-centre study of JSLE patients in India reported a mortality rate of $20 \%$ with the major predictor of mortality being the serum creatinine at the time of clinical presentation [56]. In a 23-year follow-up study from Iran, $11 \%$ of patients (20/180) with JSLE and $9 \%$ of patients (35/394) with adult SLE (a-SLE) died and the authors found that the mortality rate was not significantly different between the two groups $(p=0.4)$ but the main causes of death did differ between the groups, with more nephritis (50\% in JSLE vs. $29 \%$ in a-SLE) and more infections (40\% in JSLE vs. $29 \%$ in a-SLE) seen in the children. By multivariate analysis, seizure, proteinuria, and nephritis in JSLE had a negative prognostic effect on survival [57] and as such the importance of kidney disease as a primary cause and main predictor of death in SLE is a consistent finding in the literature [58].

\section{Improving kidney outcomes in JSLE}

Modifiable risk factors associated with a worse kidney prognosis that could potentially be influenced include the early recognition of active kidney disease, as delays can result in damage accrual. Recent international efforts in this regard indicate that the use of a panel of novel urinary biomarkers is superior to current clinical markers and integrating these into practice may enhance earlier detection and intensification of management [59]. Detailed discussion of biomarkers is beyond the scope of this paper. In addition to novel biomarkers, standardizing aspects of care may help, including when to perform a kidney biopsy and histological interpretation. Recently published, international consensus recommendations for childhood LN include these aspects and integration of these recommendations into practice should be a clinical priority [14]. The modified histological classification scores for LN incorporating active/chronic lesions seem to be more robust in predicting outcomes [60] and allow additional information on the kidney activity and chronicity status of each patient.

As this is such a heterogeneous autoimmune disease, clinical trials targeting specific biological pathways, may provide improved rates of complete response in certain patients. Examples of novel agents in the process of being evaluated for the treatment of LN are summarized in Table 2. A more personalized treat-to-target approach may explore individual immune profiling for patients who fail to achieve complete remission in order to identify predominant immune components (such as B cells, complement products, specific cytokines) that are able to act as treatment targets. This will require further scientific understanding of the biological pathways involved in active LN, and a clinically robust method of immune cell profiling that is designed and based around existing biological therapies. The identification of individual genetic risk factors may also enhance this process and perhaps proactive targeting of high-risk groups such as patients of African, Asian, or Hispanic descent who have worsened outcomes compared with Caucasians, who may benefit from a more intensive approach to treatment [61]. The addition of agents to the current induction treatment may also prove to be superior, such as adjunctive early B cell targeting or adjunctive calcineurin inhibitor [62].

As with any long-term disease, adherence to medications remains a concern. A nationwide longitudinal study in Germany on adults with SLE found that only $63 \%$ of patients self-reported high adherence [71] and another study on childhood rheumatic diseases described worse adherence in those patients required to take $>3$ daily medications [72]. Rationalizing medications when possible and regular

Table 2 Promising novel agents being evaluated for use in LN and their stage in drug development

\begin{tabular}{|c|c|c|c|}
\hline Biological target & Drug name & Studies & Phase in drug development \\
\hline B cell depletion & Obinutuzumab & {$[63]$} & Phase II \\
\hline \multirow[t]{2}{*}{ B cell growth and survival inhibitor } & Belimumab & [64] & $\begin{array}{l}\text { Food and Drug Administration (FDA), } \\
\text { European Medicines Agency (EMA), and } \\
\text { National Institute for Health and Clinical } \\
\text { Excellence (NICE) approval for use } \\
\text { in adults with LN }\end{array}$ \\
\hline & Atacicept & {$[65]$} & Phase II \\
\hline Type 1 interferon & Anifrolumab & {$[66]$} & Phase I. Phase II/III in planning \\
\hline Interleukin-6 & Tocilizumab & {$[67]$} & Phase I \\
\hline Complement & Eculizumab & {$[68]$} & Phase I \\
\hline $\mathrm{T}$ cell anti-CD40L & Dapirolizumab & {$[69]$} & Phase II \\
\hline $\mathrm{T}$ cell costimulatory pathway & Abatacept & {$[70]$} & Phase III \\
\hline
\end{tabular}


discussion to understand the complexity of adherence is therefore important.

On an international basis, the more challenging factors to address are the international variation in outcomes with regard to children with JSLE from low-/middle-income countries and this relies on mass changes in social, political, and health care agendas to provide equitable access to pediatric care across the world.

\section{Conclusions}

JSLE is a severe, lifelong condition and the overall mortality remains high across the world. Kidney involvement is independently linked to an increased risk of mortality and more damage accrual. The prompt recognition and management of $\mathrm{LN}$ is essential. Despite international consensus protocols, the evidence supporting LN management remains poor and the kidney outcomes suboptimal. There is an urgent need to improve many aspects regarding clinical care and our understanding associated with this disease, in particular the evaluation of novel therapies as adjuncts to current treatment to improve outcomes.

Funding information This project was supported by authors affiliated with the National Institute of Health Research (NIHR) Biomedical Research Centre at Great Ormond Street Hospital Children's NHS Foundation Trust and University College London, the NIHR Alder Hey Clinical Research Facility, and the UK's Experimental Arthritis Treatment Centre for Children, supported by Versus Arthritis, the Alder Hey Charity, Alder Hey Children's NHS Trust and the University of Liverpool. LUPUS UK provides financial support for co-ordination of the UK JSLE Cohort Study. We would like to thank all children, young people and their families, and the local principle investigators, research nurses and associated teams providing data to the UK JSLE Cohort Study. This work was also supported by the Alder Hey Children's Kidney Fund (LO, RW).

\section{Compliance with ethical standards}

Conflict of interest The authors declare that there are no conflicts of interest.

Disclaimer The views expressed are those of the authors and not necessarily those of the NHS, respective Universities, NIHR, or Department of Health.

Open Access This article is licensed under a Creative Commons Attribution 4.0 International License, which permits use, sharing, adaptation, distribution and reproduction in any medium or format, as long as you give appropriate credit to the original author(s) and the source, provide a link to the Creative Commons licence, and indicate if changes were made. The images or other third party material in this article are included in the article's Creative Commons licence, unless indicated otherwise in a credit line to the material. If material is not included in the article's Creative Commons licence and your intended use is not permitted by statutory regulation or exceeds the permitted use, you will need to obtain permission directly from the copyright holder. To view a copy of this licence, visit http://creativecommons.org/licenses/by/4.0/.

\section{References}

1. Hersh AO, von Scheven E, Yazdany J, Panopalis P, Trupin L, Julian L et al (2009) Differences in long-term disease activity and treatment of adult patients with childhood- and adult-onset systemic lupus erythematosus. Arthritis Rheum 61(1):13-20

2. Gottlieb BS, Ilowite NT (2006) Systemic lupus erythematosus in children and adolescents. Pediatr Rev 27(9):323-330

3. Tsioni V, Andreoli L, Meini A, Frassi M, Raffetti E, Airo P et al (2015) The prevalence and incidence of systemic lupus erythematosus in children and adults: a population-based study in a mountain community in northern Italy. Clin Exp Rheumatol 33(5):681-687

4. Kawasaki Y, Ohara S, Miyazaki K, Kanno S, Ono A, Suyama K et al (2015) Incidence and prognosis of systemic lupus erythematosus in a 35 year period in Fukushima, Japan. Pediatr Int 57(4): 650-655

5. Mackie FE, Kainer G, Adib N, Boros C, Elliott EJ, Fahy R et al (2015) The national incidence and clinical picture of SLE in children in Australia - a report from the Australian Paediatric Surveillance Unit. Lupus. 24(1):66-73

6. Lopes SRM, Gormezano NWS, Gomes RC, Aikawa NE, Pereira RMR, Terreri MT et al (2017) Outcomes of 847 childhood-onset systemic lupus erythematosus patients in three age groups. Lupus. 26(9):996-1001

7. Wu CY, Li CF, Wu QJ, Xu JH, Jiang LD, Gong L et al (2017) Chinese systemic lupus erythematosus treatment and research group registry IX: clinical features and survival of childhoodonset systemic lupus erythematosus in China. Chinese Med JPeking 130(11):1276-1282

8. Hiraki LT, Benseler SM, Tyrrell PN, Harvey E, Hebert D, Silverman ED (2009) Ethnic differences in pediatric systemic lupus erythematosus. J Rheumatol 36(11):2539-2546

9. Tektonidou MG, Lewandowski LB, Hu J, Dasgupta A, Ward MM (2017) Survival in adults and children with systemic lupus erythematosus: a systematic review and Bayesian meta-analysis of studies from 1950 to 2016. Ann Rheum Dis 76(12):2009-2016

10. Watson L, Leone V, Pilkington C, Tullus K, Rangaraj S, McDonagh JE et al (2012) Disease activity, severity, and damage in the UK juvenile-onset systemic lupus erythematosus cohort. Arthritis Rheum 64(7):2356-2365

11. Samanta M, Nandi M, Mondal R, Hazra A, Sarkar S, Sabui T et al (2017) Childhood lupus nephritis: 12 years of experience from a developing country's perspective. Eur J Rheumatol 4(3):178-183

12. Sassi RH, Hendler JV, Piccoli GF, Gasparin AA, da Silva Chakr RM, Brenol JC et al (2017) Age of onset influences on clinical and laboratory profile of patients with systemic lupus erythematosus. Clin Rheumatol 36(1):89-95

13. Weening JJ, D'Agati VD, Schwartz MM, Seshan SV, Alpers CE, Appel GB et al (2004) The classification of glomerulonephritis in systemic lupus erythematosus revisited. Kidney Int 65(2):521-530

14. Groot N, de Graeff N, Marks SD, Brogan P, Avcin T, BaderMeunier B et al (2017) European evidence-based recommendations for the diagnosis and treatment of childhood-onset lupus nephritis: the SHARE initiative. Ann Rheum Dis 76(12):1965-1973

15. KDIGO Glomerulonephritis Work Group (2012) KDIGO Clinical practice guideline for glomerulonephritis. Kidney Int Suppl 2:139 274

16. Hahn BH, McMahon MA, Wilkinson A, Wallace WD, Daikh DI, Fitzgerald JD et al (2012) American College of Rheumatology guidelines for screening, treatment, and management of lupus nephritis. Arthritis Care Res 64(6):797-808

17. Mina R, von Scheven E, Ardoin SP, Eberhard BA, Punaro M, Ilowite $\mathrm{N}$ et al (2012) Consensus treatment plans for induction therapy of newly diagnosed proliferative lupus nephritis in juvenile systemic lupus erythematosus. Arthritis Care Res 64(3):375-383 
18. Bertsias GK, Tektonidou M, Amoura Z, Aringer M, Bajema I, Berden JH et al (2012) Joint European League Against Rheumatism and European renal association-European Dialysis and Transplant Association (EULAR/ERA-EDTA) recommendations for the management of adult and paediatric lupus nephritis. Ann Rheum Dis 71(11):1771-1782

19. Zabaleta-Lanz M, Vargas-Arenas RE, Tapanes F, Daboin I, Atahualpa Pinto J, Bianco NE (2003) Silent nephritis in systemic lupus erythematosus. Lupus. 12(1):26-30

20. Oni L, Beresford MW, Witte D, Chatzitolios A, Sebire N, Abulaban $\mathrm{K}$ et al (2017) Inter-observer variability of the histological classification of lupus glomerulonephritis in children. Lupus. 26(11): 1205-1211

21. Murphy G, Isenberg DA (2019) New therapies for systemic lupus erythematosus - past imperfect, future tense. Nat Rev Rheumatol 15(7):403-412

22. Morand EF, Furie R, Tanaka Y, Bruce IN, Askanase AD, Richez C et al (2020) Trial of Anifrolumab in active systemic lupus erythematosus. N Engl J Med 382(3):211-221

23. Davidson JE, Fu Q, Ji B, Rao S, Roth D, Magder LS et al (2018) Renal remission status and longterm renal survival in patients with lupus nephritis: a retrospective cohort analysis. J Rheumatol 45(5): 671-677

24. Aragon E, Resontoc LP, Chan YH, Lau YW, Tan PH, Loh HL et al (2016) Long-term outcomes with multi-targeted immunosuppressive protocol in children with severe proliferative lupus nephritis. Lupus. 25(4):399-406

25. Zappitelli M, Duffy CM, Bernard C, Gupta IR (2008) Evaluation of activity, chronicity and tubulointerstitial indices for childhood lupus nephritis. Pediatr Nephrol 23(1):83-91

26. Hui M, Garner R, Rees F, Bavakunji R, Daniel P, Varughese S et al (2013) Lupus nephritis: a 15-year multi-centre experience in the UK. Lupus. 22(3):328-332

27. Mageau A, Timsit JF, Perrozziello A, Ruckly S, Dupuis C, Bouadma L et al (2019) The burden of chronic kidney disease in systemic lupus erythematosus: a nationwide epidemiologic study. Autoimmun Rev 18(7):733-737

28. Groot N, Shaikhani D, Teng YKO, de Leeuw K, Bijl M, Dolhain R et al (2019) Long-term clinical outcomes in a cohort of adults with childhood-onset systemic lupus erythematosus. Arthritis Rheum 71(2):290-301

29. Hari P, Bagga A, Mahajan P, Dinda A (2009) Outcome of lupus nephritis in Indian children. Lupus. 18(4):348-354

30. Taheri S, Beiraghdar F (2011) Lupus nephritis in Iranian children: a review of 60 patients. Ren Fail 33(5):499-505

31. Wong SN, Tse KC, Lee TL, Lee KW, Chim S, Lee KP et al (2006) Lupus nephritis in Chinese children-a territory-wide cohort study in Hong Kong. Pediatr Nephrol 21(8):1104-1112

32. Vachvanichsanong P, Dissaneewate P, McNeil E (2009) Diffuse proliferative glomerulonephritis does not determine the worst outcome in childhood-onset lupus nephritis: a 23-year experience in a single centre. Nephrol Dial Transplant 24(9):2729-2734

33. Shen K, Yu Y, Tang Z, Liu Z, Li L (1997) The prognosis of biopsyproven lupus nephritis in chinese patients: long term follow-up of 86 cases. Chin Med J 110(7):502-507

34. Drakoulogkona O, Barbulescu AL, Rica I, Musetescu AE, Ciurea PL (2011) The outcome of patients with lupus nephritis and the impact of cardiovascular risk factors. Curr Health Sci J 37(2):70-74

35. Chan AY, Hooi LS (2000) Outcome of 85 lupus nephritis patients treated with intravenous cyclophosphamide: a single centre 10 year experience. Med J Malaysia 55(1):14-20

36. Tsai WT, Chang HC, Wang CT, Chiang BL, Lin YT (2019) Longterm outcomes in lupus patients receiving different renal replacement therapy. J Microbiol Immunol Infect 52(4):648-653

37. Burgos PI, Perkins EL, Pons-Estel GJ, Kendrick SA, Liu JM, Kendrick WT et al (2009) Risk factors and impact of recurrent lupus nephritis in patients with systemic lupus erythematosus undergoing renal transplantation: data from a single US institution. Arthritis Rheum 60(9):2757-2766

38. Ross S, Benz K, Sauerstein K, Amann K, Dotsch J, Dittrich K (2012) Unexpected recovery from longterm renal failure in severe diffuse proliferative lupus nephritis. BMC Nephrol 13:81

39. Tanaka A, Kono H, Leung PSC, Gershwin ME (2020) Recurrence of disease following organ transplantation in autoimmune liver disease and systemic lupus erythematosus. Cell Immunol 347:104021

40. Park ES, Ahn SS, Jung SM, Song JJ, Park YB, Lee SW (2018) Renal outcome after kidney-transplantation in Korean patients with lupus nephritis. Lupus. 27(3):461-467

41. Ramirez-Sandoval JC, Chavez-Chavez H, Wagner M, Vega-Vega O, Morales-Buenrostro LE, Correa-Rotter R (2018) Long-term survival of kidney grafts in lupus nephritis: a Mexican cohort. Lupus. 27(8):1303-1311

42. Abdelrahman N, Beresford MW, Leone V, Group UKJ-oSLES (2019) Challenges of achieving clinical remission in a national cohort of juvenile-onset systemic lupus erythematosus patients. Lupus. 28(5):667-674

43. Sit JKK, Chan WKY (2018) Risk factors for damage in childhoodonset systemic lupus erythematosus in Asians: a case control study. Pediatr Rheumatol Online J 16(1):56

44. Heshin-Bekenstein M, Trupin L, Yelin E, von Scheven E, Yazdany J, Lawson EF (2019) Longitudinal disease- and steroid-related damage among adults with childhood-onset systemic lupus erythematosus. Semin Arthritis Rheum 49(2):267-272

45. Suhlrie A, Hennies I, Gellermann J, Büscher A, Hoyer P, Waldegger S et al (2020) Twelve-month outcome in juvenile proliferative lupus nephritis: results of the German registry study. Pediatr Nephrol 35(7):1235-1246

46. Lee JS, Oh JS, Kim YG, Lee CK, Yoo B, Hong S (2020) Recovery of renal function in patients with lupus nephritis and reduced renal function: the beneficial effect of hydroxychloroquine. Lupus. 29(1): $52-57$

47. Groot N, de Graeff N, Avcin T, Bader-Meunier B, Brogan P, Dolezalova P et al (2017) European evidence-based recommendations for diagnosis and treatment of childhood-onset systemic lupus erythematosus: the SHARE initiative. Ann Rheum Dis 76(11): 1788-1796

48. Petri M, Elkhalifa M, Li J, Magder LS, Goldman DW (2019) Hydroxychloroquine blood levels predict hydroxychloroquine retinopathy. Arthritis Rheumatol 72: 448-453. https://doi.org/10. 1002/art.41121

49. Ponticelli C, Escoli R, Moroni G (2018) Does cyclophosphamide still play a role in glomerular diseases? Autoimmun Rev 17(10): 1022-1027

50. Oktem O, Guzel Y, Aksoy S, Aydin E, Urman B (2015) Ovarian function and reproductive outcomes of female patients with systemic lupus erythematosus and the strategies to preserve their fertility. Obstet Gynecol Surv 70(3):196-210

51. Carson KR, Evens AM, Richey EA, Habermann TM, Focosi D, Seymour JF et al (2009) Progressive multifocal leukoencephalopathy after rituximab therapy in HIV-negative patients: a report of 57 cases from the Research on Adverse Drug Events and Reports project. Blood. 113(20):4834-4840

52. Wijetilleka S, Mukhtyar C, Jayne D, Ala A, Bright P, Chinoy H et al (2019) Immunoglobulin replacement for secondary immunodeficiency after B-cell targeted therapies in autoimmune rheumatic disease: systematic literature review. Autoimmun Rev 18(5):535541

53. Ambrose N, Morgan TA, Galloway J, Ionnoau Y, Beresford MW, Isenberg DA et al (2016) Differences in disease phenotype and severity in SLE across age groups. Lupus. 25(14):1542-1550 
54. Aggarwal A, Phatak S, Srivastava P, Lawrence A, Agarwal V, Misra R (2018) Outcomes in juvenile onset lupus: single center cohort from a developing country. Lupus. 27(11):1867-1875

55. Mahmoud GA, Shahin AA, Zayed HS, Moghazy A, Eissa BM (2018) Clinical and immunological pattern and outcome of Egyptian systemic lupus erythematosus patients: a single center experience. Lupus. 27(9):1562-1569

56. Abujam B, Gupta A, Suri D, Rawat A, Singh S (2016) Trends and predictors of mortality in childhood onset lupus in a single NorthIndian centre over 23 years: a retrospective study. Clin Exp Rheumatol 34(3):554-559

57. Fatemi A, Matinfar M, Smiley A (2017) Childhood versus adultonset systemic lupus erythematosus: long-term outcome and predictors of mortality. Clin Rheumatol 36(2):343-350

58. Harzallah A, Kaaroud H, Hajji M, Mami I, Goucha R, Hamida FB et al (2017) Predictive factors of mortality in a tunisian cohort with systemic lupus erythematosus. Saudi J Kidney Dis Transpl 28(4): 792-798

59. Smith EM, Jorgensen AL, Midgley A, Oni L, Goilav B, Putterman $C$ et al (2017) International validation of a urinary biomarker panel for identification of active lupus nephritis in children. Pediatr Nephrol 32(2):283-295

60. Hill GS, Delahousse M, Nochy D, Tomkiewicz E, Remy P, Mignon $F$ et al (2000) A new morphologic index for the evaluation of renal biopsies in lupus nephritis. Kidney Int 58(3):1160-1173

61. Hanly JG, O'Keeffe AG, Su L, Urowitz MB, Romero-Diaz J, Gordon C et al (2016) The frequency and outcome of lupus nephritis: results from an international inception cohort study. Rheumatology (Oxford) 55(2):252-262

62. Gordon S, Denunzio T, Uy A (2013) Success using tacrolimus in patients with proliferative and membranous lupus nephritis and refractory proteinuria. Hawaii J Med Public Health 72(9 Suppl 4): $18-23$

63. clinicaltrials.gov. A study to evaluate the safety and efficacy of obinutuzumab compared with placebo in participants with lupus nephritis (LN). 2015;NCT02550652

64. Navarra SV, Guzman RM, Gallacher AE, Hall S, Levy RA, Jimenez RE et al (2011) Efficacy and safety of belimumab in patients with active systemic lupus erythematosus: a randomised, placebo-controlled, phase 3 trial. Lancet. 377(9767):721-731
65. Merrill JT, Wallace DJ, Wax S, Kao A, Fraser PA, Chang P et al (2018) Efficacy and safety of atacicept in patients with systemic lupus erythematosus: results of a twenty-four-week, multicenter, randomized, double-blind, placebo-controlled, parallel-arm, Phase IIb Study. Arthritis Rheum 70(2):266-276

66. Morehouse CCL, Wang LW et al (2014) Target modulation of a type I interferon (IFN) gene signature with sifalimumab or anifrolumab in SLE patients in two open label phase 2 Japanese trials. Arthritis Rheum 66:article S313

67. Illei GG, Shirota Y, Yarboro CH, Daruwalla J, Tackey E, Takada K et al (2010) Tocilizumab in systemic lupus erythematosus: data on safety, preliminary efficacy, and impact on circulating plasma cells from an open-label phase I dosage-escalation study. Arthritis Rheum 62(2):542-552

68. Rother RP, Mojcik CF, McCroskery EW (2004) Inhibition of terminal complement: a novel therapeutic approach for the treatment of systemic lupus erythematosus. Lupus. 13(5):328-334

69. Furie RB, Bruce IN, Dorner T et al (2019) Efficacy and safety of dapirolizumab pegol (DZP) in patients with moderately to severely active systemic lupus erythematosus (SLE): A randomised, placebo (PBO)-controlled study. Annals of the Rheumatic Diseases. 78: 775-776

70. Furie R, Nicholls K, Cheng TT, Houssiau F, Burgos-Vargas R, Chen SL et al (2014) Efficacy and safety of abatacept in lupus nephritis: a twelve-month, randomized, double-blind study. Arthritis Rheum 66(2):379-389

71. Chehab G, Sauer GM, Richter JG, Brinks R, Willers R, FischerBetz R et al (2018) Medical adherence in patients with systemic lupus erythematosus in Germany: predictors and reasons for nonadherence - a cross-sectional analysis of the LuLa-cohort. Lupus. 27(10):1652-1660

72. Bugni VM, Ozaki LS, Okamoto KY, Barbosa CM, Hilario MO, Len CA et al (2012) Factors associated with adherence to treatment in children and adolescents with chronic rheumatic diseases. J Pediatr 88(6):483-488

Publisher's note Springer Nature remains neutral with regard to jurisdictional claims in published maps and institutional affiliations. 